\title{
Práticas digitais, níveis de envolvimento e pirataria: Um estudo sobre a recepção e distribuição informal de seriados de
} televisão no Brasil Vanessa Mendes Moreira de Sa

\section{Resumo}

Este estudo explora como as 'audiências piratas' assistem e distribuem seriados de televisão através da internet. Ele investiga e classifica as práticas informais por meio de revisão de literatura e do uso de estudos de caso no Brasil. 0 Brasil é uma das maiores economias do mundo e onde mais de 20 milhões de pessoas estão envolvidas na transferência não autorizada de mídia todos os dias. Além disso, defendo que, independentemente das maneiras informais de recepção, os piratas são, de fato, audiências de televisão. Embora estejam envolvidos em práticas informais, eles assistem ao mesmo conteúdo que as consideradas audiências de televisão. Portanto, uma investigação focada nas práticas informais é necessária para ampliar as noções de audiências, piratas e suas práticas de recepção de televisão.

Palavras-Chave

Pirataria. Televisão. Audiência. Participação

\section{Vanessa Mendes Moreira de Sa}

I vanessamdesa@gmail.com

Doutora em Comunicação Social pela University of Western Sydney - Austrália

\section{Introdução}

Embora menos de 50\% da população no Brasil tenha acesso à internet, o que representa mais de 82 milhões de pessoas (Nielsen Online em FEDEROWSKI, 2012), aproximadamente 41\% deste total acessa a filmes e músicas através de fontes não autorizadas (IPEA, 2012). Em outras palavras, mais de 20 milhões de pessoas no Brasil estão envolvidas no que é definida como pirataria digital. Esta informação também pode ser confirmada no Alexa.com, site de estatísticas da internet, que aponta o país entre as cinco nações que mais visitam os seguintes sites de download: piratebay.se, freakshare.com e 4shared.com. Em um estudo anterior (MENDES MOREIRA DE SA, 2011), eu argumentei que o compartilhamento informal de mídia pode estar relacionado com o 'jeitinho' brasileiro de resolver as coisas. Parece que as práticas sociais dos brasileiros indicam uma separação entre os deveres formais e as práticas cotidianas (DAMATTA, 1986). Este presente estudo explora como as 'audiências piratas' assistem televisão através de meios informais de distribuição 
pela internet. Investigo e classifico as práticas informais de compartilhamento de seriados de TV através da análise de revisão de literatura e estudos de caso no Brasil.

Cada vez mais, audiências de TV em todo 0 mundo têm utilizado a internet para acessar, distribuir e/ou facilitar 0 acesso informal de programas de TV para outros. Independentemente destas práticas muitas vezes não objetivarem fins comerciais, elas são consideradas como pirataria, uma vez que são traduzidas como roubo de propriedade intelectual e violação de direitos autorais (APCM, 2012). 0 fato que parece ser ignorado é que, independentemente da fonte, geralmente, o conteúdo visto por uma pessoa que faz 0 download é o mesmo conteúdo que pode ser visto no aparelho de TV. A principal diferença é que 0 primeiro infringe direitos de transmissão do país, definindo assim, quem se qualifica como 'audiência' e quem se qualifica como 'pirata'. Para o benefício desta pesquisa, considero pessoas que fazem download de programas como 'audiências piratas'. Em um estudo sobre a pirataria de filmes, Lobato (2011) introduz o termo 'audiências piratas'. Além dele, Cardoso, et al. (2010) utilizam o termo "audiência-pirataria" também baseando-se na noção de audiências envolvidas em práticas não autorizadas de compartilhamento de mídia. Eu utilizo o conceito de audiências piratas introduzido por estes autores, aplicando-o de forma empírica neste estudo.
Os conceitos de audiência e pirataria estão mudando simultâneamente com o que os indivíduos fazem quando utilizam as ferramentas da internet. Estudos recentes discutem 0 uso das mídiais digitais no cotidiano com foco nas práticas, tendo como objetivo entender a partir de uma perspectiva mais ampla "o que as pessoas estão fazendo com, ou em relação a mídia" (COULDRY, 2011, p. 217). Couldry (2011) exemplifica que práticas como assistir TV podem mudar de um público para 0 outro. Portanto, mesmo que o conteúdo tenha um papel importante no desencadeamento de atividades na internet, tais como a recepção e distribuição de conteúdo de maneira informal, a idéia da prática é mais importante do que 0 conteúdo em si. Este é um tema que necessita de maior aprofundamento considerando as constantes mudanças dos meios digitais de comunicação e das audiências contemporâneas.

Os métodos deste estudo incluem observação não-participativa de sites e comunidades online que fornecem links para download e para legendas. Todos os dados coletados foram codificados e analisados por temas.

\section{Entendendo práticas de pirataria}

As práticas das audiências piratas são consideradas como maneiras informais de participação em sistemas de distribuição de mídia, porque elas quebram o paradigma de mídia-audiência e exploram as alternativas 
'peer-to-peer'. Venho defendendo em estudos anteriores (MENDES MOREIRA DE SA, 2011; MENDES MOREIRA DE SA, 2014), que as práticas informais de consumo e distribuição de programas de TV no Brasil são movidas por diversas razões, como 0 alto preço dos DVDs ou da assinatura da TV a cabo, assim como os atrasos na liberação de novos episódios. Também acontecem devido a indisponibilidade de determinados seriados, e como dito anteriormente, devido as práticas culturais brasileiras. Tais práticas informais são acentuadas pelas interações sociais na internet entre os telespectadores de diferentes países, que por meio dessas interações despertam curiosidade sobre seriados que podem não estar disponíveis na programação de TV em suas cidades.

Na internet, as audiências são pesquisadoras e ativas podendo ser também trabalhadoras e colaboradoras com a finalidade de acessar e facilitar 0 acesso de seriados de TV para outros. Para compreender as práticas das audiências piratas, elas foram classificados em três categorias. Essa classificação assume a natureza ativa das audiências piratas e considera os diferentes papéis que desempenham na comunidade pirata:

Ativa e Passiva/Passiva e Ativa-Incidental; Ativa-Engajada e Social; Ativa-Trabalhadora.

Cada categoria foi criada com o objetivo de representar um nível diferente de envolvimento entre audiências na rede. É importante notar que as audiências piratas podem apresentar características de mais de uma categoria. A próxima seção apresenta a primeira categoria examinada neste estudo.

\section{Audiências piratas procurando na rede: Ativa e Passiva/Passiva e Ativa-Incidental}

Os termos "Ativa e Passiva" e "Passiva e AtivaIncidental" definem as práticas e interações das audiências que se limitam a buscar e acessar aos seriados de TV. Nesta pesquisa, esta categoria de envolvimento é considerada ativa porque as audiências piratas buscam 0 conteúdo na internet, o que é uma categoria acima de assistir TV usando um controle remoto. Como Ito (2012, p. 197) confirma "até mesmo o leecher mais casual é um consumidor mais sofisticado de mídia do que um espectador de televisão". Como definido por Cox, Collins, e Drinkwater (2010, p. 299) "[l] eechers são aqueles que fazem download ilegal de mídia, mas não disponibilizam explicitamente 0 conteúdo em troca". Esta categoria, no entanto, representa uma prática passiva, porque não utiliza plenamente as possibilidades que as ferramentas da internet oferecem, como as exploradas nas seções que estão por vir.

A maioria das audiências que baixam programas de TV através da internet estão satisfeitas em apenas acessar o conteúdo e não serem produtores ou facilitadores (NIEBORG; VAN DIJCK, 2009). As pessoas que consomem, mas não fornecem conteúdo são considerados free 
Figura 1: Revenge "Vingança” (trad. Português) Temporada 1/Episódio 1

$\rightarrow$ C D bitshare.com/files/85j7v1ij/vinganca.101.zip.html

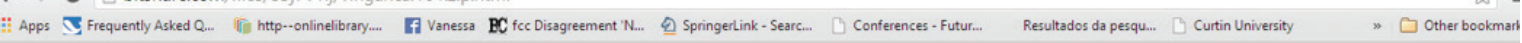

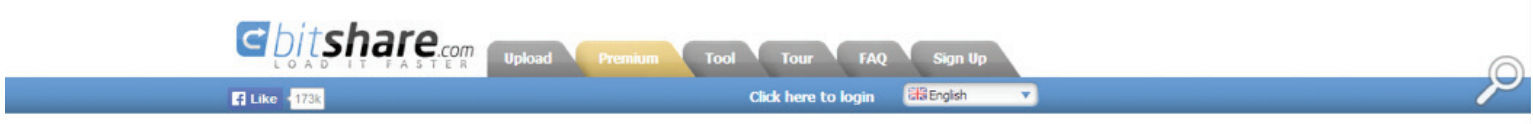

Downloading vinganca.101.zip - 140.9 MByte

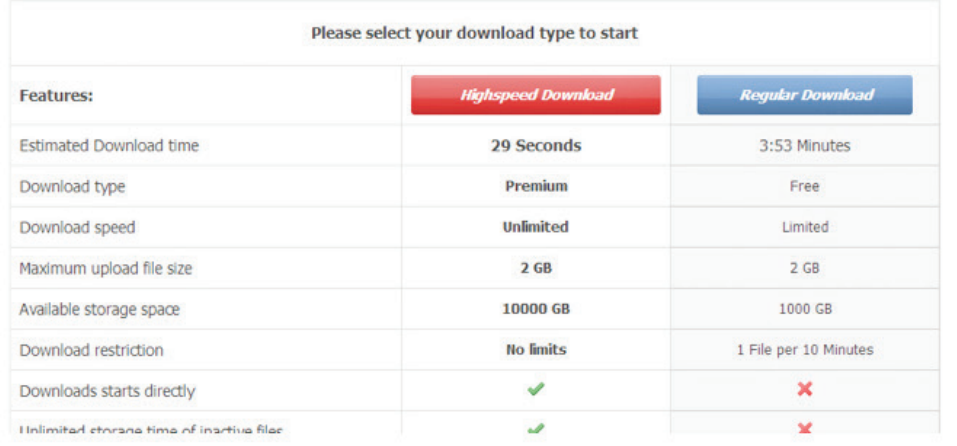

Fonte: Disponível em www.bitshare.com. Acesso em 14 fev. 2014.

riders (KRISHNAN; SMITH; TANG; TELANG, 2004). Um exemplo da categoria 'ativa e passiva' é quando as 'audiências piratas' buscam seriados em sites de hospedagem de arquivos, conhecidos como cyberlockers (KARAGANIS, 2011) como na Figura 1.

A dinâmica do site se fundamenta na relação entre usuário e servidor. De acordo com o site Alexa. com, cyberlockers são populares no Brasil. Por exemplo, 4Shared.com está no lugar $33^{\circ}$ e entre os sites mais acessados no país. Esses sites podem ser encontrados através de uma busca no Google, ou em sites e comunidades dedicadas a download de filmes (LOBATO, 2012) e programas de TV.

No Brasil, as audiências piratas usam comunidades nas mídias sociais como 0 Facebook e Orkut, e sites de download como o da
Figura 2 para distribuir e baixar seriados de TV norte-americanos. Nesses sites, as audiências piratas encontram links para o download que são organizados por série, temporada e número de episódio.

Em algumas plataformas de compartilhamento de arquivos, audiências piratas contribuem, de forma intencional ou não. A categoria 'Passiva e Ativa-Incidental' define esta prática. Ela consiste em audiências piratas seeding, o que significa disponibilizar os seus arquivos por meio de ferramentas de compartilhamento como 0 BitTorrent ou Utorrent.

Ferramentas de compartilhamento de arquivos são plataformas para download e não sites de armazenamento de arquivo, como, por exemplo, os cyberlockers. As audiências piratas devem 
Figura 2: Lista de episódios da série de TV Revenge e os links para diferentes cyberlockers

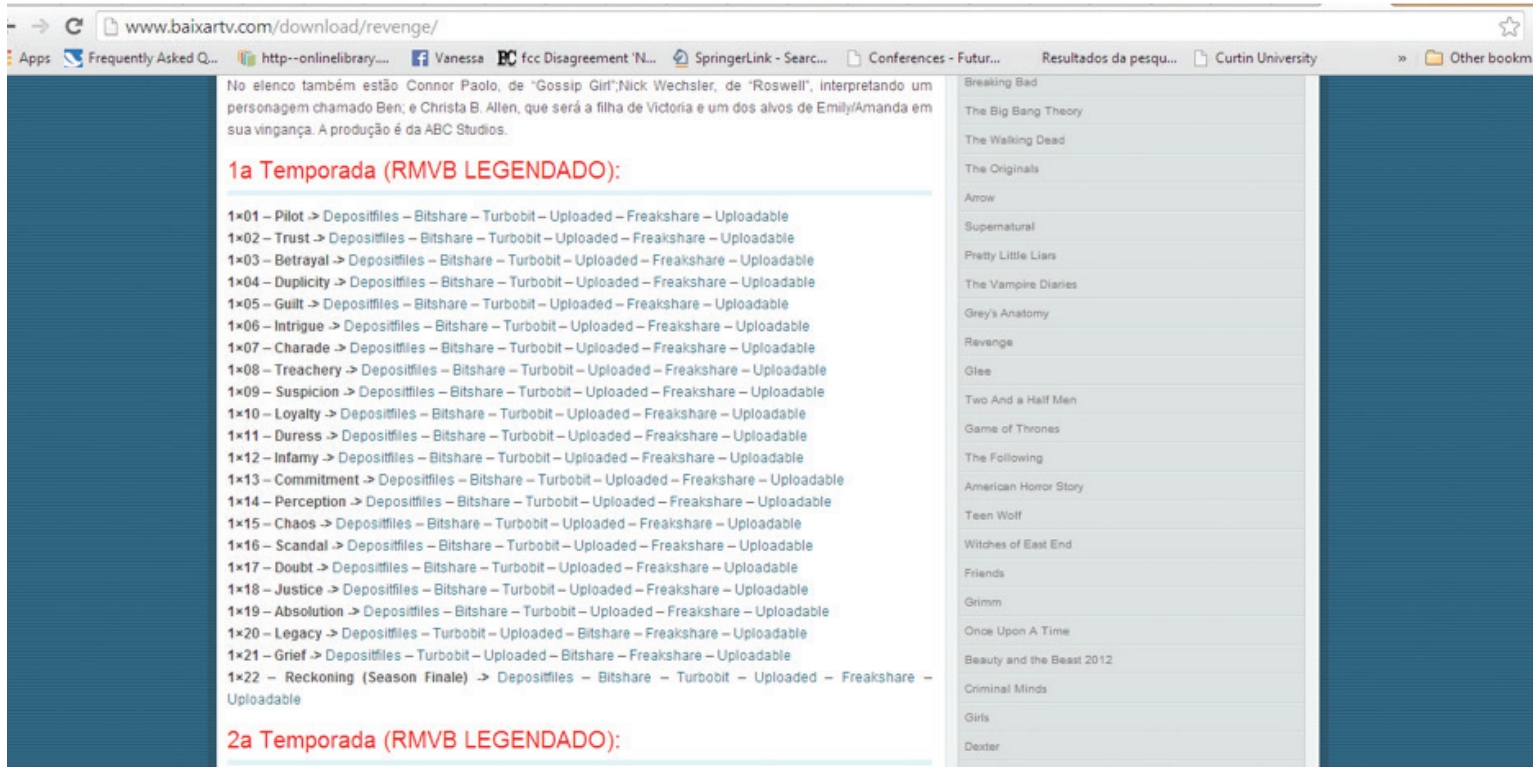

Fonte: Disponível em www.baixartv.com. Acesso em 14 fev. 2014.

procurar o conteúdo, ou torrent, em sites como

The Pirate Bay, e em seguida, eles usam 0

BitTorrent ou Utorrent para baixá-10¹. Em 14

de fevereiro de 2014, o Brasil ficou em $4^{0}$ lugar

no ranking mundial relacionado ao número de

usuários do site The Pirate Bay (www.alexa.com).

A ala esquerda da Figura 3, contém o nome do seriado de TV com a descrição do arquivo. No lado direito, há duas colunas que indicam o número de seeders, ou seja os disponibilizadores de arquivos, e os leechers.

Uma vez que as audiências piratas selecionam 0 arquivo no The Pirate Bay, elas podem utilizar as ferramentas de compartilhamento para baixar 0 arquivo. Por exemplo, BitTorrent conecta 0 usuário a partes do mesmo arquivo, a partir de diferentes usuários conectados na rede e naquela ferramenta, em vez de baixar um arquivo inteiro de uma fonte, como no caso do cyberlocker. Além disso, a tecnologia torrent permite ao usuário baixar partes dos arquivos, mesmo quando os outros usuários da ferramenta de compartilhamento não tiverem concluído o download (VINCENT, 2007). Isso significa que, todos os usuários do BitTorrent compartilham os seus próprios arquivos automaticamente, e assim sendo, este sistema aumenta exponencialmente a velocidade e a eficiência de compartilhamento (SMITH, 2007; VINCENT, 2007). Esta troca acontece enquanto os usuários estão baixando e depois de terem baixado os arquivos. 
Figura 3: Top 100 seriados de TV mais baixados no site do The Pirate Bay

\begin{tabular}{|c|c|c|c|}
\hline $\begin{array}{l}\text { Video } \\
\text { (TV shows) }\end{array}$ & 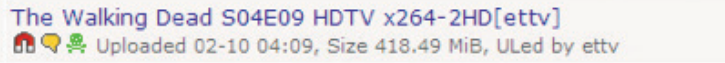 & 23343 & 1361 \\
\hline $\begin{array}{l}\text { Video } \\
\text { (TV shows) }\end{array}$ & $\begin{array}{l}\text { The Big Bang Theory S07E15 HDTV } \times 264-\text { LOL [eztv] } \\
\text { A0 } \square \div \text { Uploaded } 02-07 \text { 05:37, Size } 136.64 \mathrm{MiB} \text {, ULed by eztv }\end{array}$ & 14122 & 409 \\
\hline $\begin{array}{l}\text { Video } \\
\text { (TV shows) }\end{array}$ & $\begin{array}{l}\text { The Big Bang Theory S07E14 HDTV x264-LOL [eztv] } \\
\text { 으 } \square . \frac{9}{-} \text { Uploaded } 01-31 \text { 03:07, Size } 142.56 \mathrm{MiB} \text {, ULed by eztv }\end{array}$ & 9900 & 266 \\
\hline $\begin{array}{l}\text { Video } \\
\text { ( TV shows) }\end{array}$ & 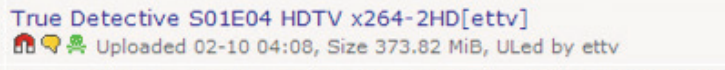 & 7961 & 508 \\
\hline $\begin{array}{l}\text { Video } \\
\text { (TV shows) }\end{array}$ & $\begin{array}{l}\text { How I Met Your Mother S09E17 HDTV x264-EXCELLENCE[ettv] } \\
\text { A } \square \div \frac{9}{9} \text { Uploaded } 02-0402: 38 \text {, Size } 154.73 \mathrm{MiB} \text {, ULed by ettv }\end{array}$ & 7896 & 229 \\
\hline $\begin{array}{l}\text { Video } \\
\text { (TV shows) }\end{array}$ & $\begin{array}{l}\text { How I Met Your Mother S09E16 HDTV x264-KILLERS [eztv] } \\
\text { A } \square \text { : Uploaded 01-28 02:45, Size } 186.26 \text { MiB, ULed by eztv }\end{array}$ & 7649 & \\
\hline $\begin{array}{c}\text { Video } \\
\text { (TV shows) }\end{array}$ & 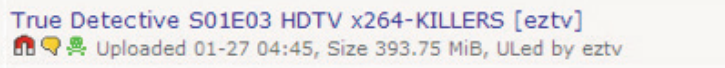 & 6616 & 364 \\
\hline $\begin{array}{l}\text { Video } \\
\text { (TV shows) }\end{array}$ & $\begin{array}{l}\text { Arrow S02E13 HDTV } \times 264-\text { LOL[ettv] } \\
\text { A } 9.9 \text { Uploaded } 02-06 \text { 03:00, Size } 260.19 \text { MiB, ULed by ettv }\end{array}$ & 6302 & 315 \\
\hline $\begin{array}{l}\text { Video } \\
\text { (TV shows) }\end{array}$ & $\begin{array}{l}\text { Top Gear } 21 \times 02 \text { HDTV x264-FoV [eztv] } \\
\text { 으: Uploaded 02-09 23:28, Size } 613.81 \text { MiB, ULed by eztv }\end{array}$ & 6104 & 422 \\
\hline $\begin{array}{l}\text { Video } \\
\text { (TV shows) }\end{array}$ & $\begin{array}{l}\text { The Big Bang Theory S07E13 HDTV } \times 264-\text { LOL [eztv] } \\
\text { ค } ๑: 9 \text { Uploaded } 01-10 \text { 02:46, Size } 159.11 \mathrm{MiB} \text {, ULed by eztv }\end{array}$ & 5867 & \\
\hline $\begin{array}{l}\text { Video } \\
\text { (TV shows) }\end{array}$ & 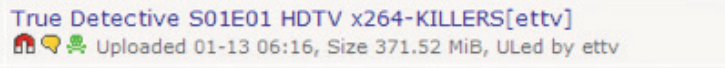 & 5495 & 322 \\
\hline $\begin{array}{c}\text { Video } \\
\text { (TV shows) }\end{array}$ & 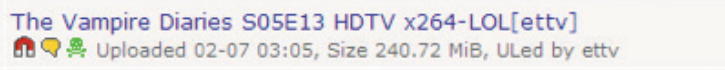 & 5410 & \\
\hline Video & The Walking Dead S04E09 HDTV x264-2HD [eztv] & 4911 & \\
\hline
\end{tabular}

Fonte: Disponível em thepiratebay.se Acesso em 14 fev. 2014. A imagem foi alterada para este artigo, com o objetivo de chamar a atenção para a lista.

Com a tecnologia torrent, os usuários também são distribuidores de conteúdo uma vez que há um intercâmbio contínuo de arquivos.

Consequentemente, em algum momento todos os usuários são seeders e leechers. Desta forma, essa situação cria um ambiente onde todos os compartilhadores de arquivos são responsáveis pela distribuição não autorizada de conteúdo. 0 usuário, no entanto, pode escolher parar de compartilhar arquivos uma vez que 0 seu download for concluído. Voltando assim ao status de free rider de consumo.

Para as audiências piratas, ferramentas de busca na internet oferecem uma imensa variedade de programação, especialmente quando se leva em conta as formas autorizadas (por exemplo: Netflix e Itunes) e não autorizadas para a obtenção de conteúdo, bem como as habilidades de busca na Internet de um indivíduo. Nightingale (2011) discute as diferenças entre pesquisa e descoberta na internet. A pesquisa traz uma satisfação individual, especialmente uma vez que a descoberta é atingida e recolhida. A satisfação emocional, no entanto, pode ser diminuída se a "caça", como ela define, é facilmente resolvida. Nightingale (2011) argumenta que as informações podem ser facilmente encontradas na internet e desta forma o pesquisador recebe-as como se fossem um presente. Sendo assim, a facilidade de se encontrar 
produtos de mídia na internet resulta em uma diminuição em como o seus valores são percebidos. A definição do valor de um produto corresponde a princípio ao valor de troca tendo uma conotação financeira e não um significado emocional.

A grande disponibilidade de conteúdo em plataformas de compartilhamento de arquivos, parece ser uma prática socialmente aceitável entre os seus usuários, contribuindo para a desvalorização financeira do conteúdo. Assim, acontece um 'desentendimento' com o que é percebido pelas autoridades como uma atividade ilegal. Ao tomar como garantida a abundância de conteúdo na internet, as audiências piratas podem não compreender 0 valor financeiro do conteúdo de mídia. Na internet, o consumo de informações, serviços e até mesmo o conteúdo não leva à escassez de um produto da mesma forma que ocorre com bens materiais (DE ARAUJO PINHEIR0, 2007, p. 51). Portanto, levando em consideração que há uma diferença entre o valor de troca financeiro e ao valor de troca de sentidos na internet, é possível entender melhor as práticas de download e interações de rede. Estas discussões sobre a internet são importantes, pois mudam a percepção da pirataria e do que é certo ou errado em uma sociedade. Neste cenário, cria-se oportunidade para discussões sobre a abundância e a escassez de disponibilidade, além da distribuição de conteúdo (BAUWENS, 2008). Em suma, na internet audiências buscam, encontram e consomem conteúdo. Isso pode ser categorizado como via ativa-passiva de envolvimento ou, com uma ligeira contribuição para a rede, uma categoria ativa incidental de envolvimento. Audiências piratas podem acessar aos programas de TV e, em seguida, podem deixar de compartilhar na rede. Elas também podem desejar conectar-se com outros colegas que partilham um gosto comum. Esta conectividade indica a segunda categoria de envolvimento introduzida neste artigo, que é categoria AtivaEngajada e Social'.

\section{Audiências piratas e redes sociais: Participação 'Ativa-Engajada e Social'}

Audiências piratas utilizam as redes sociais como uma plataforma para interagir com outros colegas para promover, discutir e compartilhar conteúdo de mídia para fins sociais e razões afetivas. Argumenta-se que as interações estabelecidas em comunidades virtuais motivam 0 consumo e distribuição através do compartilhamento social. Embora a evolução das tecnologias de informação e comunicação tenham tido um grande impacto sobre a participação das audiências, este não é um assunto novo, nem limitado a tecnologias digitais (Carpentier, 2009). Por exemplo, as duas formas de participação que esta pesquisa se concentra nesta categoria são: (I) fornecer feedback, bem como o poder do 'boca-a-boca', e (II) 0 compartilhamento social. Ambas as práticas existiam entre as audiências antes da internet. Estas, porém, foram aprimoradas devido à evolução tecnológica e ao maior número 
de pessoas envolvidas nessas atividades. Por outro lado, são práticas, com um impacto significativo sobre a comunidade pirata.

0 download de seriados de TV têm sido influenciado por interações 'boca-a-boca' entre as audiências em fóruns de discussão, contribuindo com a curiosidade do espectador e levando-os a baixar programas que não estão disponíveis em canal aberto ou a cabo. As audiências devem estar atualizadas com os episódios, a fim de tomar parte nas discussões na internet, e até mesmo fora dela, para assim evitar os conhecidos spoilers ou estragadores de surpresas (BROWN; BARKHUUS, 2006). Além disso, as discussões aumentam a conscientização das pessoas sobre novos programas de TV, lançamentos de episódios e informação de como acessá-los online. Audiências piratas podem participar de comunidades em sites de redes sociais (por exemplo, Facebook e Orkut) ou através de fóruns de discussão na internet (por exemplo, TV without pity). Elas podem ler artigos relacionados asériesou ler discussões sobre compartilhamento de arquivos (por exemplo, o blog TorrentFreak). Jenkins (2006) afirma que esses exemplos demonstram que "a pirataria torna-se uma forma de promoção". Alguns membros da indústria reconhecem a importância de fãs e 0 poder do boca-a-boca para promover conteúdo (JENKINS, 2006).

Além de aumentar a consciência de programas de TV por meio de discussões, as audiências piratas podem compartilhar suas experiências com outras pessoas na rede por meio do compartilhamento social de conteúdo. Por exemplo, audiências podem contar para seus amigos sobre conteúdos que elas preferem. Se estes amigos gostarem, eles também podem redistribuir o conteúdo nas suas redes. É claro que "[e]les não simplesmente repassam o conteúdo de forma estática, já que eles transformam ou recontextualizam 0 conteúdo para que ele atenda melhor as suas necessidades sociais e expressivas" (GREEN; JENKINS, 2011, p. 123). A alegria da descoberta, conforme explicado no trabalho da Nightingale (2011), pode levar à redistribuição de um determinado conteúdo. Assim, a circulação do mesmo nas redes pode ocorrer voluntariamente de um ponto para o outro. Esta dinâmica tem sido rotulada de "viral", o que poderia ser considerada uma extensão do boca-a-boca por ser uma prática relacionada à promoção de conteúdos (BURGUESS, 2008).

Sites de mídia social, como YouTube e Facebook, têm sido utilizados excessivamente para este tipo de compartilhamento. Green e Jenkins (2011) utilizaram a audição da cantora amadora Susan Boyle para o programa de TV Britain's Got Talent como exemplo. 0 vídeo se tornou viral nas redes sociais. Pessoas compartilharam o vídeo, mesmo em países onde 0 show não foi ao ar.

Outro exemplo pode ser visto na Figura 4, que apresenta a página no Facebook do programa de TV da ABC, Revenge. Como muitas outras 


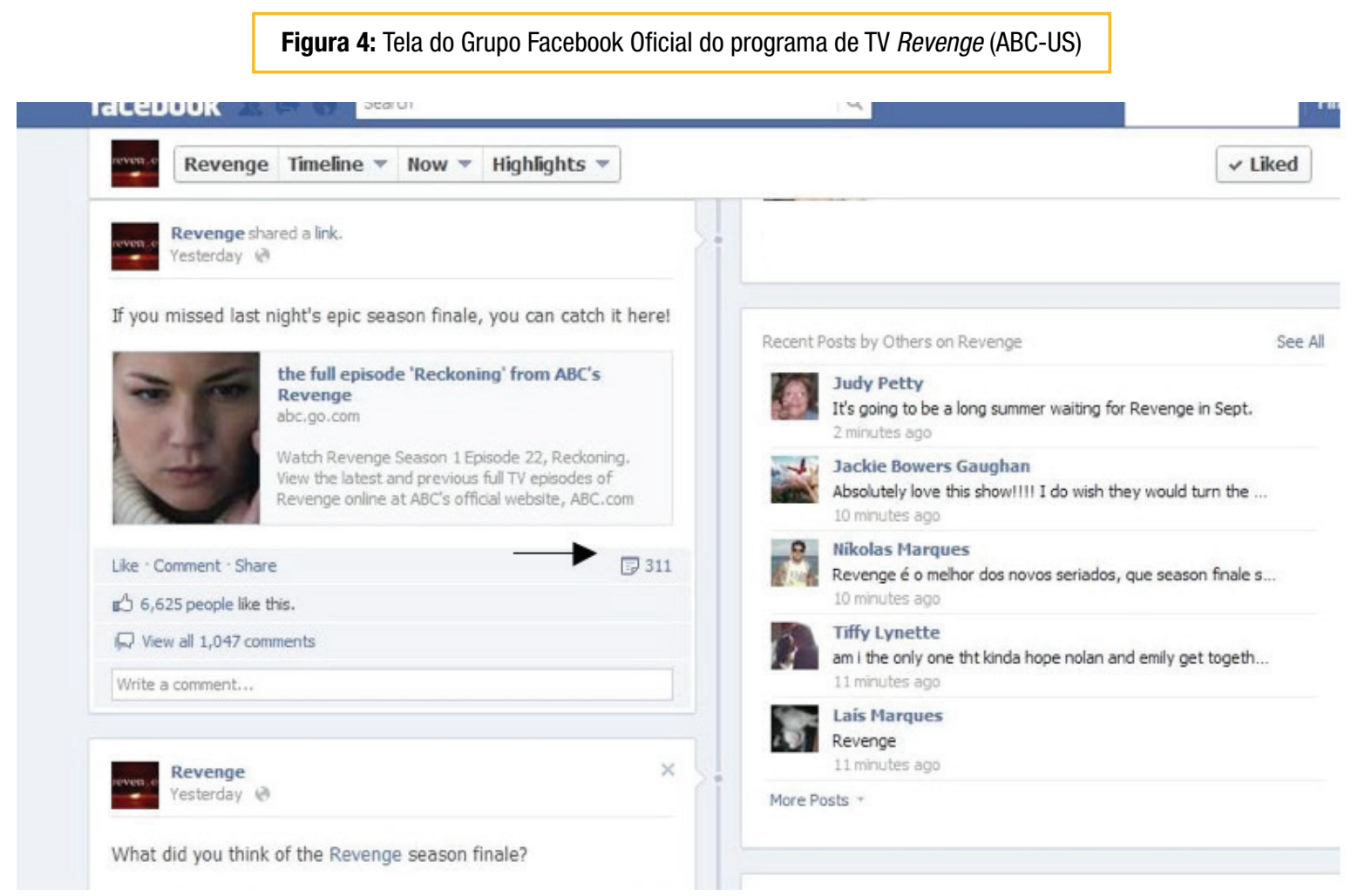

Fonte: Disponível em https://www.facebook.com/RevengeABC. Acesso em 26 maio 2012. Imagem alterada (seta).

redes norte-americanas, a $\mathrm{ABC}$ fornece um link direcionando os usuários para o seu site, para que eles assistam a episódios online.

Em seguida, os residentes dos EUA podem compartilhar os links dos episódios na sua rede de amigos no Facebook.

Ao disponibilizar o seriado na internet, compartilhamento social é um resultado esperado pelos proprietários de direitos autorais e este tem sido o caso do programa de TV Revenge. Compartilhamento social também pode ocorrer através do compartilhamento informal e muitas vezes não autorizado em sites como You Tube, e esta foi a situação no exemplo da Susan Boyle. No entanto, neste caso o compartilhamento social ajudou a promover Boyle, bem como o programa de TV, Britain's Got Talent (HOLMWO0D, 2009). Assim, embora a prática tenha sido a mesma em ambos os casos, pode-se argumentar que a legitimidade da fonte original é o que distingue 'audiências' de 'piratas' aos olhos das redes de TV e proprietários de direitos autorais. É importante compreender os papéis das audiências e como elas utilizam as tecnologias digitais antes de fazer definições precipitadas.

A amostra estudada no Brasil mostrou que 0 'boca-a-boca', os meios de comunicação de massa e a utilização de mídias sociais eram as fontes mais comuns de onde as audiências 
piratas aprenderam sobre programas de TV e lançamento de novos episódios. Estas práticas de boca-a-boca também operam em um ambiente off-line, embora de forma alterada. Com as redes sociais, no entanto, o volume de interação com outras pessoas é maior do que presencialmente, especialmente quando se trata de discutir algo que todos tenham interesse, como por exemplo, um seriado de TV. Assim, nota-se que as audiências piratas utilizam as comunidades no Orkut e Facebook não somente para baixar episódios, mas também as procuravam para praticar brincadeiras e jogos uns com os outros. Esses jogos sendo relacionados a determinadas séries de TV. Por exemplo, os participantes da comunidade no Orkut do seriado norteamericano da CW Supernatural fazem perguntas como "qual personagem da série que a pessoa acima se parece?" e assim, outros membros interagiam entre si. Eles também trocam spoilers e notícias, discutem episódios e realizam outras atividades de fãs.

Embora a distribuição de compartilhamento social possa ser vista como uma prática de trabalho, já que os telespectadores estão trabalhando de graça para promover 0 conteúdo de outra pessoa, ela foi categorizada como 'Ativa-Engajada e Social'. 0 conteúdo que está sendo compartilhado representa adquire um significado diferente do que 0 que foi originalmente proposto. Por exemplo, uma pessoa pode enviar um link de um programa de TV porque acha que 0 amigo irá gostar de um personagem ou da trama. É aceitável dizer, portanto, que a distribuição via compartilhamento social pode representar características de ambas as categorias: 'AtivaEngajada e Social' e 'Ativa-Trabalhadora'. Esta última categoria será explicada a seguir.

\section{Audiências piratas e 0 trabalho colaborativo: Ativa-Trabalhadora}

A última categoria explorada neste artigo é a AtivaTrabalhadora'. Talvez seja a mais controversa das práticas porque as audiências são constantemente alvo das autoridades não só pela utilização da propriedade intelectual de forma não autorizada, mas também por facilitar 0 acesso a outros. É importante afirmar que as audiências piratas consideradas neste estudo não têm retorno financeiro como sua principal motivação para o trabalho que realizam. Elas se concentram em interações sociais e afetivas no lugar da troca comercial. Lessig (2008), Benkler (2006) e Terranova (2004) são alguns dos estudiosos que sugerem que as colaborações não focadas no aspecto financeiro são diferentes das dinâmicas de mercado tradicionais, porque elas são movidas por motivações afetivas e são classificadas como trabalho imaterial ou livre. Na minha pesquisa, eu achei a categoria 'Ativa-Trabalhadora' significativa entre as audiências piratas brasileiras.

As práticas de audiências piratas são elevadas a uma categoria diferente, uma vez que participação e envolvimento com outras audiências e com 0 
conteúdo de mídia torna-se trabalho. As audiências consideradas neste estudo facilitam 0 acesso aos seriados de TV através do envio de arquivos, organização de links para acesso ou através da produção de legendas em sua língua local.

Produção e colaboração são consideradas as melhores formas de mostrar a dedicação e 0 envolvimento das audiências na rede (NIEBORG; VAN DIJCK, 2009). Nota-se que este trabalho colaborativo é geralmente voluntário. Muitas audiências, no entanto, estabelecem um compromisso afetivo com outras audiências, bem como com o conteúdo de mídia, e isso aumenta a sua vontade de participar deste trabalho colaborativo (TERRANOVA, 2004). Lessig (2008, p. 149) explica que "motivações focadas em dinheiro são diferentes das motivações de cunho social". Benkler (2006, pp. 6-7) confirma dizendo: "às vezes [...] estas colaborações não mercantis podem ser as maioresmotivadoras e podem permitir que pessoas criativas trabalhem em projetos de informação de forma mais eficiente do que seria em um tradicional sistema de mercado e empresas".

Assim, alguns dos conceitos apresentados na categoria 'Ativa-Engajada e Social' podem ser alocados na categoria 'Ativa-Trabalhadora', porque motivos afetivos podem implicar na vontade de participar. A sensação de pertencimento também é um incentivo para o fortalecimento dos laços nas redes porque as audiências podem trabalhar em equipes. Assim, elas se sentem motivadas a provocar mudanças enquanto imersas em relações sociais onde outras audiências também concordam que 0 sistema de distribuição televisiva de certa forma é "fascista" (Lessig, 2008, p. 44) e juntas elas encontram uma maneira de acessar e facilitar 0 acesso ao conteúdo.

0 compartilhamento de arquivos de programas de TV por audiências piratas brasileiras não seria possível sem esta categoria de prática de trabalho ativo. Esta pesquisa centra-se em três tipos de facilitadores: Seeders, administradores de sites de download e fansubbers ou Legenders.

\section{Seeders}

Seeders são audiências piratas que capturam o conteúdo de mídia e distribuem-no online. Conforme visto na categoria Ativa e Passiva/ Passiva e Ativa-Incidental', os seeders podem ser qualquer pessoa utilizando plataformas de torrent para download de conteúdo, desde que não interrompa o processo de seeding. Inegavelmente, esses personagens têm o papel fundamental em manter a comunidade pirata operante, porque eles são os guardiões da distribuição informal de conteúdo.

\section{Distribuição informal através de sites}

Após o trabalho dos seeders ser realizado, as audiências piratas no Brasil, atuando como facilitadores, irão organizar e redistribuir os seriados de TV através de seus sites de download, blogs, canais do YouTube, comunidades online e outras plataformas. 
Figura 5: Pasta personalizada, onde programas de TV baixados, neste caso, os episódios Arrow, podem ser arquivados

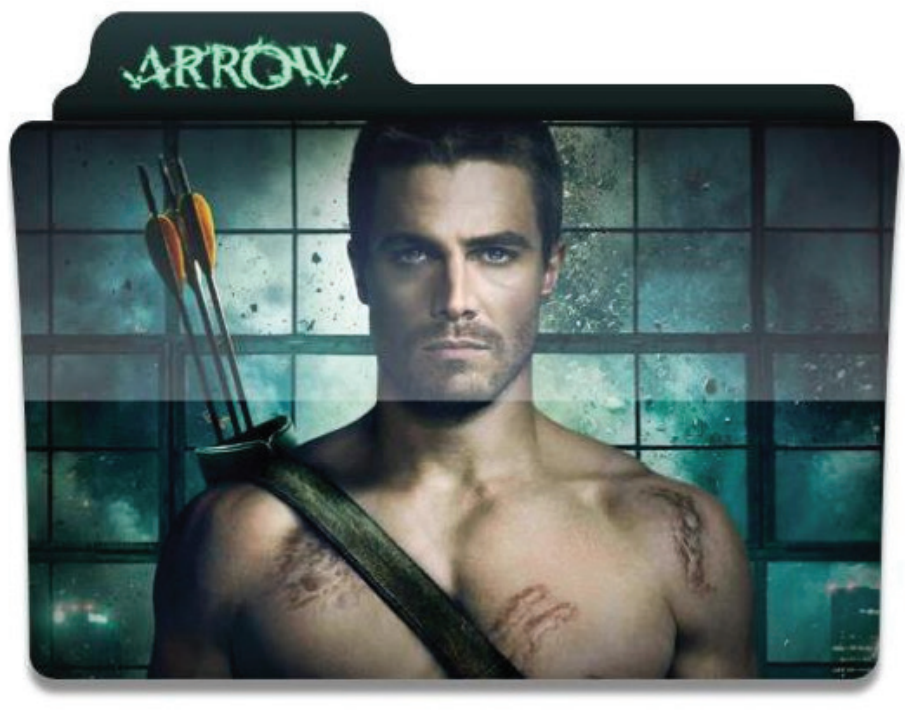

Fonte: Disponível em página no Facebook do grupo SeriesFD. Acesso em 21 de out. 2012.

Eu observei alguns aspectos únicos das redes de audiências piratas no Brasil. Em primeiro lugar, os sites de download podem prestar serviços distintos, tais como a transmissão ao vivo de programas de TV no momento de exibição nos EUA. Essas transmissões ao vivo são populares porque há muitas audiências piratas brasileiras que não conseguem esperar algumas horas até que 0 arquivo de vídeo esteja disponível. No entanto, as transmissões ao vivo informais podem ser pouco confiáveis, pois percebi que muitas audiências estavam insatisfeitas com a qualidade do streaming. No entanto, ainda assim elas assistiram os vídeos e deixaram comentários dizendo que iriam assistir o episódio novamente mais tarde uma vez que 0 vídeo fosse divulgado.

Em segundo lugar, alguns sites também oferecem de graça produtos digitais para as audiências piratas. Por exemplo, a Figura 5 mostra uma pasta digital criada por administradores do site para download 'SeriesFD' para o programa de TV Arrow. 0 site também oferece pastas digitais para outras séries de TV dos EUA. Desta forma, depois de baixar um episódio, as audiências piratas podem arquivá-lo em uma pasta personalizada.

0 lançamento deste produto digital alinha com a afirmação de De Kosnik (2012) que uma das motivações mais fortes para compartilhamento de arquivos é 0 arquivamento. De Kosnik (2012) compara a "coleta digital" pirata com práticas off-line de coleta. Ela enfatiza que os riscos e as responsabilidades são maiores com as práticas online em função do potencial de atingir um número maior de pessoas, em comparação aos antigos meios de compartilhamento, por exemplo, a troca de fitas VHS com gravações. 
Também foi observado que os sites de download estavam investindo em plataformas que permitissem aos usuários baixar programas de televisão gratuitamente de aparelhos variados. Em 2 de novembro de 2011, os administradores do site 'Baixar Seriados', anunciaram no Facebook que eles estavam trabalhando em uma versão especial do site que poderia ser usado em smartphones e tablets.

Além de oferecer serviços promocionais, tais como publicidade, anúncios em redes sociais, merchandising, pastas personalizadas e distribuição através de multiplataformas, os sites de download também têm como objectivo lançar novos episódios 0 mais depressa possível. Na verdade, esta parece ser uma prioridade para muitos administradores. Assim, as práticas de distribuição informal das audiências piratas brasileiras são de certa forma competitivas, com enfoque na própria marca e se assemelham a distribuição tradicional de programas de TV.

\section{Fansubbing}

Os fansubbers também são facilitadores de distribuição de TV informal, porque criam legendas que são utilizadas por audiências piratas que baixam seriados e não conseguem entender a língua original. Nesta pesquisa, investigo um grupo de fansubbers no Brasil conhecidos como Legenders, que predominantemente traduzem programas dos EUA e do Reino Unido para o Português.

0s Legenders podem trabalhar sozinhos oufazer parte de equipes afiliadas ou não ao site brasileiro e fonte de legendas, Legendas.TV (LTV). Muitos Legenders passam a noite acordados legendando os seriados de TV para que eles possam ser liberados o mais rápido possível. Esta situação ocorre principalmente no caso de programas de TV mais populares, ou seja, aqueles com o maior número de downloads. No entanto, o trabalho dos Legenders tem cunho profissional no sentido de trabalho em equipe e qualidade. Além disso, os padrões estabelecidos pelos administradores do site LTV refletem padrões profissionais como por exemplo, na duração da exposição da legenda e do número de caracteres por página (BOLD, 2012).

Estes legendadores amadores também usam as mídias sociais (Facebook, Orkut, Twitter e outros) e sites oficiais como plataformas para a promover novas séries que eles irão legendar. Assim, eles constroem uma audiência em torno daquela determinada série. As mídias sociais também sãos usadas para avisar as audiências piratas sobre a disponibilidade de legendas.

Observei numa das atividades promocionais dos Legenders, a preocupação com a sensibilização social. Em outubro de 2012 várias equipes aderiram à campanha "Outubro Rosa" que arrecada dinheiro para a prevenção do câncer de mama.

Várias equipes de Legenders fizeram parte da campanha utilizando as suas páginas no Facebook para disponibilizar informação sobre auto exame e informações gerais sobre o câncer de mama. É possível argumentar que apesar de amadores, 0 


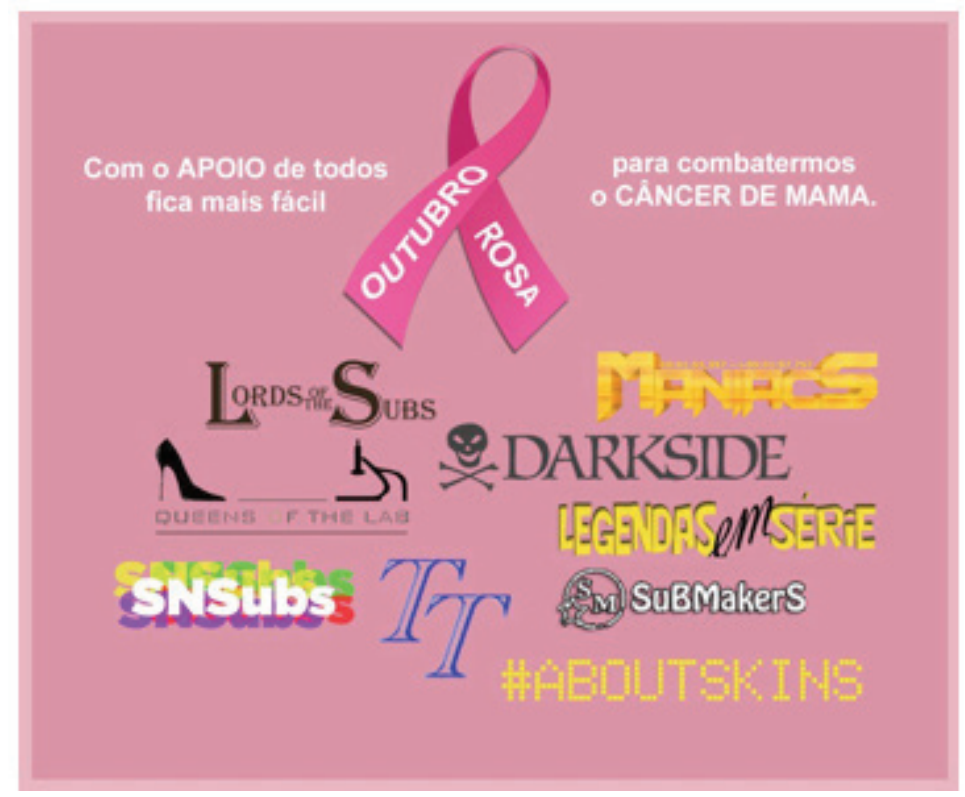

Fonte: Disponível em Página no Facebook da equipe 'Legendas em Serie’. Acesso em 13 out. 2012.

trabalho de Legenders apresenta semelhanças com práticas de trabalho profissionais como, distribuição de trabalho, relações públicas, entre outros.

\section{Conclusão}

Seguindo 0 argumento de Couldry (2011), este estudo analisou as práticas das audiências piratas através de seus diferentes níveis de envolvimento na rede. Eu formulei a classificação dos níveis de envolvimento, levando em conta a natureza ativa das audiências piratas e os diferentes papéis que elas desempenham. Três níveis foram definidos: (1) Ativa e Passiva/Passiva e Ativa-Incidental; (2) Ativa-Engajada e social; (3) Ativa-Trabalhadora.

Esta tipologia me ajudou a organizar pesquisas existentes sobre o tema, contribuindo com um melhor entendimento das práticas informais. 0s níveis também me permitiram explorar e distiguir de forma mais eficaz as audiências piratas brasileiras e suas particularidades.

A prática de assistir TV está mudando. Na era digital, as audiências buscam conteúdo independentemente de ser exibido em seu país. Audiências utilizam recursos digitais, organizam-se em comunidades e criam sistemas alternativos de distribuição em resposta ao que é percebido por este público como preços injustos, indisponibilidade ou qualquer outro obstáculo que as impeça de acessar 0 conteúdo que almejam. Essas audiências são consideradas audiências piratas e suas práticas informais correspondem a seus níveis de participação na internet. 
Ao fundamentar a pesquisa em estudos de casos no Brasil, eu busquei tornar visível uma atividade que é considerada criminosa, mas ao mesmo tempo, explorar a forma como audiências criam e mantêm uma rede pirata de recepção e distribuição de programas de TV. Este é um tema que precisa continuar a ser pesquisado, considerando que as práticas e tecnologias estão em desenvolvimento assim como os conceitos de "audiências" e "piratas".

\section{Referências}

APCM. Pirataria na internet. Sao Paulo, SP, 2012.

Disponível em: http://www.apcm.org.br/pirataria.php > . Acesso em: 29 de Março de 2013.

BAUWENS, M. Michel Bauwens P2P lecture in Australia (complete video). P2P Foundation.The Foundation for Peer to Peer Alternatives, February 14 2008. Disponível em: < http://p2pfoundation.ning.com/ video/2003008:Video:105 > . Acesso em: 29 de Novembro de 2013.

BENKLER, Y. The wealth of networks. How social production transforms markets and freedom. New Haven, CT: Yale University Press, 2006.

BOLD, B. The power of fan communities: An overview of fansubbing in Brazil. Tradução em Revista, Rio de Janeiro, RJ, v. 11, 2012. Disponível em: < http://www. maxwell.lambda.ele.puc-rio.br/trad_em_revista.php?s trSeca $0=0$ UTPUT\&fas $=178 \& \mathrm{NrSeca} 0=44>$. Acesso em: 29 de Novembro de 2013.

BURGUESS, J. 'All your chocolate rain are belong to us'. Viral video, YouTube and the dynamics of participatory culture. Video Vortex Reader: Responses to YouTube. Amsterdam, Holland: Institute of Network Cultures, p. 101-109, 2008.

BROWN, B.; BARKHUUS, L. The television will be revolutionized: effects of PVRs and filesharing on television watching. Proceedings of the SIGCHI conference on $\mathrm{H}$ uman Factors in computing systems. Montreal, Quebec, Canada: ACM, p. 663$666,2006$.

CARDOSO, G.; LIMA, T.; VIEIRA, T. Audience's paradigms and their new paths (from mainstream to "piracy"). Cost Action Transforming Audiences, Transforming Societies (IS0906), 2010.

CARPENTIER, N. Participation is not enough: The conditions of possibility of mediated participatory practices. European Journal of Communication, London, England, v. 24, n. 4, p. 407-420, 2009.

COULDRY, $N$. The necessary future of the audience. In: NIGHTINGALE, V. (Ed.). The handbook of media audiences. Mladen, MA: Wiley-Blackwell, 2011.

COX, J.; COLLINS, A.; DRINKWATER, S. Seeders, leechers and social norms: Evidence from the market for illicit digital downloading: Elsevier B.V., v. 22, n. 4, p. 299-305, 2010.

DAMATTA, R. 0 que faz o brasil, Brasil? Rio de Janeiro: Rocco, 1986.

DE ARAUJO PINHEIRO, M. Comunicação, consumo e produção de si [Communication, consumption and self production]. In: COUTINHO, I. e MENDES DA SILVEIRA JR., P. (Ed.). Comunicação: technologia e identidade. Rio de Janeiro, RJ: Mauad, 2007. p. 51-64.

DE KOSNIK, A. T. The collector is the pirate.

International journal of communication (Online), $n$. Journal Article, p. 523, 2012.

FEDEROWSKI, B. Acesso à Internet no Brasil chega a 82,4 mi de usuários—pesquisa. Reuters Brasil, 2012. GREEN, J.; JENKINS, H. Spreadable media. How audiences create value and meaning in a networked economy. In: NIGHTINGALE, V. (Ed.). The handbook of media audiences. Malden, MA: Wiley-Blackwell, 2011. p.109-127. 
HOLMWO0D, L. TV ratings: Britain's Got Talent hits high note. TV Ratings: The Guardian, 2009.

IPEA. Download de músicas e filmes no Brasil: Um perfil dos piratas online. Comunicados do IPEA: Secretaria de Assuntos Estratégicos da Presidência da República, 2012.

ITÕ, M. Contributors versus leechers: Fansubbing ethics and hybrid public culture. In: ITÕ, M.;OKABE, D., et al (Ed.). Fandom unabound: otaku culture in a connected world. New Haven, CT: Yale University Press, 2012.

JENKINS, H. When piracy becomes promotion. Reason, v. 38, n. 7, p. 78, 2006. ISSN 00486906. Disponível em: < http://reason.com/ archives/2006/11/17/when-piracy-becomes-promotion >. Acesso em: 29 de Novembro de 2013.

KARAGANIS, J. Rethinking piracy. Social Science Reserach Council. 2011

LESSIG, L. Remix: Making art and commerce thrive in the hybrid economy. New York, NY: Penguin Press, 2008.

LOBATO, R. Constructing the pirate audience: on popular copyright critique, free culture and cyber-libertarianism.

Media International Australia, Incorporating Culture \& Policy, n. 139, p. 113-123, 2011.

Shadow economies of cinema:

mapping informal film distribution. London, England: Palgrave Macmillan, 2012.

MENDES MOREIRA DE SA, V. Internet piracy as a hobby: What happens when the Brazilian Jeitinho meets television downloading? Global Media Journal Australian Edition. Sydney, NSW. 5, 2011.

The collaborative production of amateur subtitles for pirated TV shows in Brazil. In: FREDRIKSSON, M. e ARVANITAKIS, J. (Ed.). Piracy: Leakages of modernity: Litwin Books, LLC, 2014. NIEBORG, D.; VAN DIJCK, J. Wikinomics and its discontents: a critical analysis of Web 2.0 business manifestos. New Media \& Society, London, England, v. 11, n. 5, p. 855-874, 2009.

NIGHTINGALE, V. Search and social media. In: NIGHTINGALE, V. (Ed.). The handbook of media audiences. Malden, MA: Wiley-Blackwell, 2011. p.86-108.

SMITH, A. D. BitTorrent shares movies, TV shows and controversy. The Dallas Morning News. Dallas, TX, 2007.

TERRANOVA, T. Network culture: politics for the information age. London; Ann Arbor, MI: Pluto Press, 2004.

VINCENT, C. B. Bit torrent, Grokster, and why entertainment and Internet lawyers need to prepare for the fair use argument for downloading TV shows. Journal of Internet Law, v. 10, n. 11, p. 1, 2007. 
Digital Practices, levels of engagement and piracy: A study of informal viewing and distribution of television shows in Brazil

\section{Abstract}

This study explores how 'pirate audiences' watch television shows through informal means of distribution over the internet. It investigates and categorises informal practices of television downloading through analysis of literature review and case studies in Brazil. Brazil is one of the world's largest economies and where over 20 million people are involved in unauthorised downloading of media everyday. Moreover, I argue that regardless of the informal ways of viewing, pirates are, in fact, audiences. Though they are audiences involved in informal practices, they still watch the same television content. Therefore, a practice oriented research is needed to extend the notions of audiences and pirates and their television viewing practices.

\section{Keywords}

Piracy. Television. Audience. Participation.
Prácticas digitales, niveles de compromiso y la piratería: un estudio de visualización y distribución de televisión informal muestra en Brasil

\section{Resumen}

Este estudio explora cómo el publico audiovisual pirata observa televisión por los medios de distribución informal atraves de internet. Investiga y categoriza practicas informales de descarga de televisión por medio del análisis de revisión bibliográfica y estudio de casos en Brasil. Brasil es una de las economías más grandes del mundo y donde más de 20 millones de personas están involucradas en la descarga no autorizada de los medios de comunicación todos los día. Ademas se argumenta que, independientemente de las maneras informales de visualización, los piratas son, de hecho, el público. Aunque son públicos involucrados en las prácticas habituales, que todavía ven el mismo contenido de televisión. Por lo tanto, es necesaria una investigación orientada a la práctica de extender las nociones de public y de los piratas y sus prácticas de visualización de televisión.

Palabras-Clave

La piratería. Television. Publico audiovisual. Participación. 


\section{Expediente}

A revista E-Compós é a publicação científica em formato eletrônico da Associação Nacional dos Programas de Pós-Graduação em Comunicação (Compós). Lançada em 2004, tem como principal finalidade difundir a produção acadêmica de pesquisadores da área de Comunicação, inseridos em instituições do Brasil e do exterior.

\section{E-COMPÓS I www.e-compos.org.br I E-ISSN 1808-2599}

Revista da Associação Nacional dos Programas

de Pós-Graduação em Comunicacão.

Brasília, v.17, n.2, mai./ago. 2014.

A identificação das edições, a partir de 2008

passa a ser volume anual com três números.

\section{CONSELHO EDITORIAL}

Afonso Albuquerque, Universidade Federal Fluminense, Brasil Alberto Carlos Augusto Klein, Universidade Estadual de Londrina, Brasil Alex Fernando Teixeira Primo, Universidade Federal do Rio Grande do Sul, Brasil Rio Grande do Sul, Brasi

Ana Gruszynski, Universidade Federal do Rio Grande do Sul, Brasil Ana Silvia Lopes Davi Médola, Universidade Estadual Paulista, Brasil André Luiz Martins Lemos, Universidade Federal da Bahia, Brasi Ângela Freire Prysthon, Universidade Federal de Pernambuco, Brasil Antônio Fausto Neto, Universidade do Vale do Rio dos Sinos, Brasil Antonio Carlos Hohlfeldt, Pontifícia Universidade Católica do Rio Grande do Sul, Brasil Antonio Roberto Chiachiri Filho, Faculdade Cásper Líbero, Brasi Arlindo Ribeiro Machado, Universidade de São Paulo, Brasil Arthur Autran Franco de Sá Neto, Universidade Federal de São Carlos, Brasil Benjamim Picado, Universidade Federal Fluminense, Brasil César Geraldo Guimarães, Universidade Federal de Minas Gerais, Brasil Cristiane Freitas Gutfreind, Pontifícia Universidade Católica do Rio Grande do Sul, Brasil Denilson Lopes, Universidade Federal do Rio de Janeiro, Brasil Denize Correa Araujo, Universidade Tuiuti do Paraná, Brasi Edilson Cazeloto, Universidade Paulista , Brasil

Eduardo Vicente, Universidade de São Paulo, Brasil Eneus Trindade, Universidade de São Paulo, Brasil Erick Felinto de Oliveira, Universidade do Estado do Rio de Janeiro, Brasi Florence Dravet, Universidade Católica de Brasília, Brasil Gelson Santana, Universidade Anhembi/Morumbi, Brasi Gilson Vieira Monteiro, Universidade Federal do Amazonas, Brasil Gislene da Silva, Universidade Federal de Santa Catarina, Brasil Guillermo Orozco Gómez, Universidad de Guadalajara Gustavo Daudt Fischer, Universidade do Vale do Rio dos Sinos, Brasil Hector Ospina, Universidad de Manizales, Colômbia Herom Vargas, Universidade Municipal de São Caetano do Sul, Brasil Ieda Tucherman, Universidade Federal do Rio de Janeiro, Brasil Inês Vitorino, Universidade Federal do Ceará, Brasil Janice Caiafa, Universidade Federal do Rio de Janeiro, Brasil Jay David Bolter, Georgia Institute of Technology Jeder Silveira Janotti Junior, Universidade Federal de Pernambuco, Brasi João Freire Filho, Universidade Federal do Rio de Janeiro, Brasil John DH Downing, University of Texas at Austin, Estados Unidos Ana Carolina Damboriarena Escosteguy, Pontifícia Universidade Católica do

José Afonso da Silva Junior, Universidade Federal de Pernambuco, Brasil José Carlos Rodrigues, Pontifícia Universidade Católica do Rio de Janeiro, Brasil José Luiz Aidar Prado, Pontifícia Universidade Católica de São Paulo, Brasil José Luiz Warren Jardim Gomes Braga, Universidade do Vale do Rio dos Sinos, Brasil Juremir Machado da Silva, Pontifícia Universidade Católica do Rio Grande do Sul, Brasil Laan Mendes Barros, Universidade Metodista de São Paulo, Brasil Lance Strate, Fordham University, USA, Estados Unidos Lorraine Leu, University of Bristol, Grã-Bretanha Lucia Leão, Pontifícia Universidade Católica de São Paulo, Brasil Luciana Panke, Universidade Federal do Paraná, Brasil Luiz Claudio Martino, Universidade de Brasília, Brasil Malena Segura Contrera, Universidade Paulista, Brasil Márcio de Vasconcellos Serelle, Pontifícia Universidade Católica de Minas Gerais, Brasil Maria Aparecida Baccega, Universidade de São Paulo e Escola Superior de Propaganda e Marketing, Brasil Maria das Graças Pinto Coelho, Universidade Federal do Rio Grande do Norte, Brasil Maria Immacolata Vassallo de Lopes, Universidade de São Paulo, Brasil Maria Luiza Martins de Mendonça, Universidade Federal de Goiás, Brasil Mauro de Souza Ventura, Universidade Estadual Paulista, Brasil Mauro Pereira Porto, Tulane University, Estados Unidos Nilda Aparecida Jacks, Universidade Federal do Rio Grande do Sul, Brasil Paulo Roberto Gibaldi Vaz, Universidade Federal do Rio de Janeiro, Brasil Potiguara Mendes Silveira Jr, Universidade Federal de Juiz de Fora, Brasil Renato Cordeiro Gomes, Pontifícia Universidade Católica do Rio de Janeiro, Brasil Robert K Logan, University of Toronto, Canadá

Ronaldo George Helal, Universidade do Estado do Rio de Janeiro, Brasil Rosana de Lima Soares, Universidade de São Paulo, Brasi Rose Melo Rocha, Escola Superior de Propaganda e Marketing, Brasil Rossana Reguillo, Instituto de Estudos Superiores do Ocidente, Mexico Rousiley Celi Moreira Maia, Universidade Federal de Minas Gerais, Brasi Sebastião Carlos de Morais Squirra, Universidade Metodista de São Paulo, Brasil Sebastião Guilherme Albano da Costa, Universidade Federal do Rio Grande do Norte, Brasil

Simone Maria Andrade Pereira de Sá, Universidade Federal Fluminense, Brasi Tiago Quiroga Fausto Neto, Universidade de Brasília, Brasil Suzete Venturelli, Universidade de Brasília, Brasil Valerio Fuenzalida Fernández, Puc-Chile, Chile Veneza Mayora Ronsini, Universidade Federal de Santa Maria, Brasil Vera Regina Veiga França, Universidade Federal de Minas Gerais, Brasil

\section{COMISSÃO EDITORIAL}

Cristiane Freitas Gutfreind I Pontifícia Universidade Católica do Rio Grande do Sul, Brasil Irene Machado I Universidade de São Paulo, Brasil

Jorge Cardoso Filho I Universidade Federal do Reconcavo da Bahia, Brasil / Universidade Federal da Bahia, Brasil

CONSULTORES AD HOC

Adriana Amaral, Universidade do Vale do Rio dos Sinos, Brasil

Alexandre Rocha da Silva, Universidade Federal do Rio Grande do Sul, Brasi Arthur Ituassu, Pontifícia Universidade Católica do Rio de Janeiro, Brasil Bruno Souza Leal, Universidade Federal de Minas Gerais, Brasil Elizabeth Bastos Duarte, Universidade Federal de Santa Maria, Brasil Francisco Paulo Jamil Marques, Universidade Federal do Ceará, Brasi Maurício Lissovsky, Universidade Federal do Rio de Janeiro, Brasil Suzana Kilpp, Universidade do Vale do Rio dos Sinos, Brasil Vander Casaqui, Escola Superior de Propaganda e Marketing, Brasil

EDIÇÃO DE TEXTO E RESUMOS I Susane Barros SECRETÁRIA EXECUTIVA I Helena Stigger EDITORAÇÃo ELETRÔNICA I Roka Estúdio
COMPÓS I www.compos.org.br

Associação Nacional dos Programas de Pós-Graduação em Comunicação

Presidente

Eduardo Morettin

Universidade de São Paulo, Brasil

eduardomorettin@usp.br

Vice-presidente

Inês Vitorino

Universidade Federal do Ceará, Brasil

ines@ufc.br

Secretária-Geral

Gislene da Silva

Universidade Federal de Santa Catarina, Brasil

gislenedasilva@gmail.com 